\title{
Relationship between Knowledge Management, Empowerment and Self Efficacy to Learning Organization
}

\author{
${ }^{1}$ Dian Wulandari, ${ }^{2}$ Billy Tunas, ${ }^{3}$ Widodo Sunaryo \\ ${ }^{1,2,3}$ Post Graduate Program,Universitas Pakuan Bogor, Indonesia
}

\begin{abstract}
The research objective is to identify the correlation between knowledge management, empowerment and self efficacy as independent variables with learning organization as a dependent variable when tested both individually and simultaneously. The research used a sequential explanatory design mixed method which quantitative research was conducted first and followed by qualitative research to obtain more comprehensive output. This research was carried out at Elementary Public School Teachers, in Bogor, Indonesia. A total of 230 from 45 schools were sampled to collect data. This research applied co-relational technique to assess the degree of relationship among those variables.
\end{abstract}

The main conclusions of quantitative research are: there is a positive and significant correlation between the dependent variables with dependent variables. This findings was supported with qualitative result revealing that when knowledge management, empowerment and self efficacy are higher, they will increase learning organization score. Other factors which have a positive correlation in increasing learning organization is amounted of $30,5 \%$.

Keywords: learning organization, knowledge management, empowerment, self efficacy.

\section{INTRODUCTION}

Education is expected to be a major part of human resource development pillars that not only survived, but competent and superior in controlling the situation even resulted in innovations that enable people to improve their quality of life. The magnitude of the expectations in demanding the educational output requires all members of educational institutions, specially teachers, to perform their role effectively to produce competent graduates. In order to achieve good quality, it requires teachers to develop on-going learning activities or known as learning organization. Teachers need to develop a positive and constructive perspective to the role and learners, constantly learn various methods and facilitation techniques, continuously add property of learning resources and maintain the newness, master the skill of utilizing information and communication technologies applied in the learning process. Another thing is that the teacher must be able to give an example of how to be a creative person, scientific attitude, eager to find out new things, consistently uses a variety of learning resources, and especially teachers need to set an example as a lifelong learner. Also in the school transformed into a learning organization, teacher training has a way of looking and solving problems systemically so that its performance impact on improving the competitiveness of the school.

In fact the activity of continuos learning among teachers is not optimal, teachers have not been consistently used the personal ability, not optimal in constructing positive phenomenon and solving problem, the teacher is not maximized in the use of management support for interaction, communication and collaboration among members, teachers have not fully participated active in formulating and implementing the vision and mission of the organization, and especially in using the framework of systemic thinking in problem solving and effort to improve the achievement of the school.

Based on the background and the results of the identification of the problem, the formulation of the problem is: 1) Is there a relationship between knowledge management with learning organization ?,2) Is there a relationship between the empowerment of human resources with a learning organization?, 3) Is there a relationship between self-efficacy with learning organization ?, 4) Are there relationship among knowledge management, empowerment of human resources, and self-efficacy together with the learning organization?. 


\section{LiteratURE REVIEW}

Gareth R.Jones (2013) formulates a learning organization as an organization that deliberately designing, constructing the structure, culture and strategy in a way that enhance and maximize the potential of organizational learning, helping managers make un-programmed decisions so the organization is able to adapt, modify and change the environment in order to increase organizations opportunities to survive. Four (4) levels of learning should be encouraged, namely: 1) individual: personal mastery and mental mode 2) groups: interaction, sharing, synergy; 3 ) organizational structure and culture, reward systems, facilitating learning, 4) inter organizational: cooperation with suppliers and distributors to increase the input and output of the organization.

Peter Senge (2012) as one of the initiators of learning organization states that learning institutions (schools) can be designed and implemented as a learning organization through efforts involving all parts of the school system (teachers, parents, students, business people and community) in the expression of their aspirations, build awareness and joint capabilities through the development of five (5) learning discipline in order to encourage the achievement of the organization and a better future, namely personal mastery, shared vision, mental models, team learning and system thinking.

Based on the theories that have been presented, it can be synthesized that in a school organization, learning organization of teachers refer to activities that teachers do to participate to create a climate of learning, use the facilities of learning activities of the school, and continuous learning to improve problem-solving abilities, measured using research instruments in the form of a questionnaire based on the indicators: 1) the behavior of a commitment to lifelong learning, 2) the consistent use of personal abilities, 3) the use of constructive thinking in understanding the phenomena around, 4) use a positive approach to problem solving, 5) the participation of members in the formulation of a vision together, 6) behavioral commitments to implement the vision of the organization, 7) utilization management support for interaction between groups, 8) collaboration between teachers in the learning and 9) the use of templates systemic thinking in solving problems.

Paul Quintas (2002) formulating knowledge management as a study on how to create a learning environment that helps development and work creation, collection, use of personal knowledge and organizational sustainability. The indicators are: 1) the sharing of knowledge, 2) utilizing stories for the transfer of learning, 3) riviu post action, learn from experience, 4) intelligence agencies to identify specific information, 5) developing the database, 6) acquiring skills, 7 ) learn from mistakes, the culture of "no blame", and 8) implementation of advanced classes to share expertise.

William R. King (2009) formulates knowledge management as planning, organizing and controlling the people, processes and systems within the organization to ensure that all assets of the relevant knowledge are developed and used effectively. Activities are: 1) acquisition 2) creation (through socialization, combination, externalization and internalization), 3) refinement: selecting, extracting, purifying and optimizes knowledge, 4) storage, 5) transfer, 6) sharing and 7) utilization.

Based on exposure to earlier theories, can be synthesized that in educational organizations, the knowledge management of teachers is the assessment of the activities that teachers manage and add value to the school through increased knowledge of the school, and are actively acquiring, repairing, storing, evaluating, distributing, and using the knowledge and experience inside and outside the organization, measured using the instrument in the form of a questionnaire based on the indicators: 1) knowledge acquisition, 2) knowledge refinement, 3) knowledge storing, 4 ) knowledge evaluation, 5) knowledge distribution, and 6) knowledge application.

Empowerment in this research is the empowerment of human resources in psychological empowerment as an individual member of the organization by the leadership.

Hersey et al (2008) formulate empowerment as an extension of a delegation which managers can share and distribute to a subordinate's authority. Empowerment steps of members of the organization are: 1) identifying which members are suitable to be contributors, 2) educating, 3) sharing a secret with explaining what was going on, 4) making a daily accomplishments record, 5) ensuring consistency of operational standards to ensure the quality, 6) experimenting with every element, product or service with a method that is well-documented, 7) loyalty to subordinates because they will become a partner, 8) enlarging responsibility of subordinates in decision making, 9) celebrating the success, 10) being part of the group, charitably hearts of members, meaning strengthen mutual efforts. 
Colquitt et al (2011) reported psychological empowerment as the energy that is rooted in the belief that the tasks in one's work contributes to the greater goal. Empowerment is a representation of intrinsic motivation where the tasks of the job itself essentially of reward and satisfaction. Aspects of empowerment are: 1) meaningfulness, a sense of meaning, passionate, 2) self-determination, a sense of being able to determine matters related to the scope of work, 3) competent, strengthening confidence in the capability of members, 4) impact, a sense that the action taken to bring the impact on the performance of an organization's success.

Based on the previous description it can be synthesized that in school organization, teachers' empowerment is the activities undertaken by principals in optimizing the potential, strength, skill or energy of teachers with added authority, establishing performance high standards, strengthening selfdetermination, strengthening the sense of competent, awarding, tolerance for failure, as well as strengthening the sense of an impact on the teachers in order to improve the performance and contribution of teachers towards self-development and the school where they taught, measured using the instrument in the form of a questionnaire based on the indicators: 1) the addition of authority, 2) establishment of high performance standard, 3) the strengthening of self-determination, 4) strengthening a sense of competence, 5) awards, 6) tolerance to failure, and 7) strengthening a sense of impact.

Feist et. Al (2013) to formulate self-efficacy as a person's beliefs about the ability or its ability to cope with a particular situation or behave as expected. Factors that affect self-efficacy, namely 1) the previous experience, in this case the experience of successful previous tends to increase self-efficacy, 2) modeling of social, self-efficacy tend to increase when a person observes others are considered equivalent capable of performing the same action, 3) persuasion social, meaningful expression of influential people who could decrease or increase self-efficacy, and 4) physical and emotional state, anxiety, fear and excessive stress potentially lower self-efficacy, while mild anxiety and being able to improve efficacy.

Fred Luthans (2011) formulates self-efficacy as a person's beliefs about his ability to mobilize the motivation, cognitive resources and concrete actions needed to successfully carry out special duties on certain situations. Self efficacy is not only determined by the capabilities and resources, but by perception or belief that one can use the capabilities and resources to accomplish specific tasks. According Luthans, the main source of information that determines self efficacy are: 1) the experience of previous successful proficient or, 2) vicarious experiences, 3) social persuasion, and 4) physical and psychological state. Luthans explained that the process of self-efficacy begins with weighing the task, evaluating and integrating information about the self-perception abilities. Scale or level of selfefficacy can be seen from 1) magnitude: the amount or level of difficulty of the task is believed a person that he is able to carry, 2) strength, which is indicative whether the magnitude is strong and persistent when it appears difficult in duties, and 3) generalization: the perception or expectation that similar success can occur on other assignments in different situations.

Based on the exposure, it can be synthesized that in organizational education, self-efficacy of teachers is the self-assessment of teachers regarding the abilities to work and to complete tasks as teachers with a specific successful rate, measured using the instrument in the form of a questionnaire based on the indicators: 1) challenging tasks, 2) the complexity of the task, 3) reward for task completion, 4) the previous experience, 5) social persuasion, 6) physical and emotional state, 7) models of successful practices, 8) prestige on the success, 9) optimism to succeed with high selfefficacy.

Based on above description the following hypothesis is formulated:

- Knowledge management is positively related to learning organization.

- Empowerment is positively related to learning organization.

- Self-Efficacy is positively related to learning organization.

- Knowledge management, empowerment and self-efficacy are simultaneously related to learning organization.

\section{Methodology}

This study applies Sequential Explanatory Design Mixed Method where quantiative study is ahead of qualitative study to examine the relationship between variables tested in the study using three 
independent variables through data obtained from questionnaires. The independent variable is Knowledge Management $\left(\mathrm{X}_{1}\right)$, Empowerment $\left(\mathrm{X}_{2}\right)$, and Self-Efficacy $\left(\mathrm{X}_{3}\right)$, while the dependent variable is the Learning Organization (Y).

The relationship among variables in the study described in Fig.1 below:

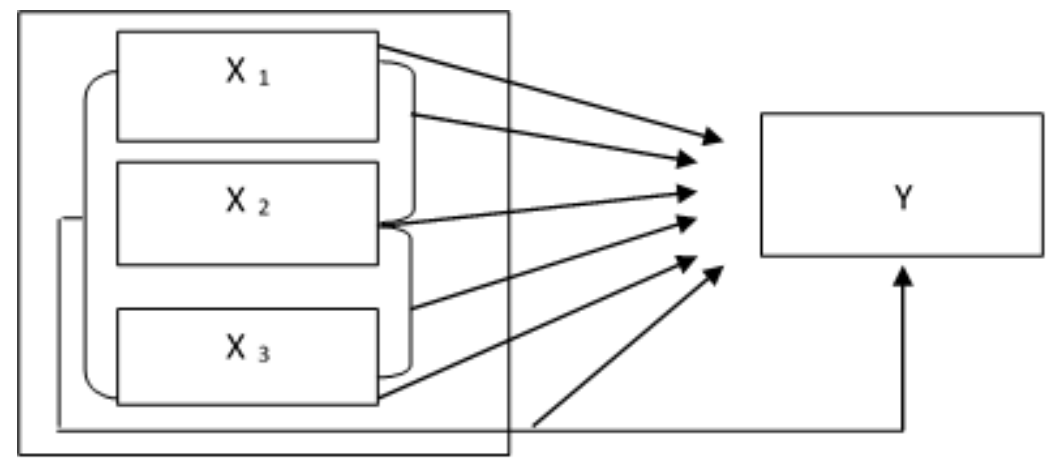

Figure1. Theoretical framework

Where, $\mathrm{Y}=$ Learning Organization

$\mathrm{X}_{1}=$ Knowledge Management

$\mathrm{X}_{2}=$ Empowerment

$\mathrm{X}_{3}=$ Self-Efficacy

The sample of this study is 230 public elementary school teachers of out of 1079 teachers using multistage proportional random sampling from 45 elementary school with an "A" accreditation in the city of Bogor, West Java Indonesia. Hypothesis testing is conducted by using regression analysis to determine the influence of one or more independent variables on the dependent variable. The normality assumptions are prerequisites to proceed to further test. Hypothesis testing is performed at a significance level of 0.05 .

Qualitative study for the purpose of confirmation was performed through observation and interview to key informant as well as conducting focus group discussion. The focus of this qualitative phase of the research is to get an explanation, answers, facts or evidence regarding the following questions:

- Do the data on relationship of knowledge management, empowerment and self-efficacy to learning organization obtained through quantitative research have the same tendency with qualitative data?

- Are there other factors beyond knowledge management, empowerment and self-efficacy related to learning organization in public elementary school teachers specifically to the ones with an "A" accredited organization in the city of Bogor, Indonesia?

\section{RESULTS AND DISCUSSION}

The teachers of listed organizations were asked to participate in the survey by responding their opinions for four different measures in knowledge management, empowerment, self-efficacy and learning organization. The data normality is performed with Liliefors test. The scores are $0.015,0.029$ and 0.034 respectively below the critical value for $\mathrm{N}=230$ which is 0.058 leading to conclusion that the data is normally distributed. The result of hypothesis testing with the strength of association is depicted below.

Table1. Summary of Test

\begin{tabular}{|c|c|c|c|c|}
\hline No & Relationship & Coefficient of Correlation & $\mathrm{t}_{\text {test }}$ & Conclusion \\
\hline 1 & $\mathrm{X}_{1}>\mathrm{Y}$ & $\mathrm{R}_{\mathrm{y} 1}=0.814$ & $21.14^{* *}$ & Hypothesis 1, Accepted \\
\hline 2 & $\mathrm{X}_{2}>\mathrm{Y}$ & $\mathrm{r}_{\mathrm{y} 2}=0.302$ & $4.78^{* *}$ & Hypothesis 2, Accepted \\
\hline 3 & $\mathrm{X}_{3}>\mathrm{Y}$ & $\mathrm{r}_{\mathrm{y} 3}=0.214$ & $3.31^{* *}$ & Hypothesis 3, Accepted \\
\hline 4 & $\mathrm{X}_{1}, \mathrm{X}_{2}, \mathrm{X}_{3}>\mathrm{Y}$ & $\mathrm{r}_{\mathrm{y} 123}=0.834$ & $4.22^{* *}$ & Hypothesis 4, Accepted \\
\hline
\end{tabular}

$* P<0.05, * * P<0.01$

Observing the table, hypothesis testing shows there is a significant positive correlation between Knowledge Management and Learning Organization, with correlation coefficient $(r)=0.814$ indicating the level of the relationship is very strong. Based on the coefficient of determination $\left(\mathrm{r}^{2}\right)=$ 
0.662 , it is concluded that knowledge management contributed $66.2 \%$ of the learning organization. Considerable contribution implies the need to increase knowledge management if the organization wants to improve the learning activities of its members. Schools where teachers implement effective knowledge management, is characterized by continuous expansion of knowledge, learning resources continues to grow and to be utilized to the optimum, innovative works is more likely to be created, cooperation to share insights, garnering more powerful and application of new knowledge to increase. Teachers who consistently implement these activities will be trying to learn and discover the most effective ways to manage and improve the knowledge of self and the group. The close linkages according to Michael J.Marquardt (2002) that when members of the organization working on something related to knowledge, so in essence they are learning. Increased activity of learning organization will be effective if the entire school community is committed to implementing knowledge management activities that support the atmosphere and member of the school learning activities.

Similarly, the hypothesis testing shows that there is a significant positive correlation between the Learning Organization Empowerment with correlation coefficient $(r)=0.302$, and the coefficient of determination $\left(\mathrm{r}^{2}\right)=0.091$ indicating that contributing factors to the learning organization empowerment by $9.1 \%$ of the learning organization. Determination of high performance standards and the provision of additional powers and responsibilities by the school head with an expression that motivates teachers and enhanced rewards program for the learning outcomes of teachers will have an impact on the improvement of learning activities teachers, in addition, principals need to facilitate activities to increase the competence of teachers so that learning is effective. Generally, observation from quantitative and qualitative data indicated that the implementation of the empowerment of teachers by principals is not yet comprehensive. The school principal is perceived to have delivered sentences to motivate teachers and assured teachers that the performance impact on the progress of the school, but has not been accompanied by setting high performance standards and examples of how to carry out direct learning activities of good quality. The school principal motivates teachers to try something new, but is not yet committed to establish the novelty of such a standard that must be met by teachers. The head masters show tolerance towards mistakes and gave teachers the opportunity to repair the fault but is not accompanied by real constructive action against teachers who have failed. This situation can make the teacher lose the direction to achieve progress and excellence. Teachers assess principals as providing flexibility in class management including rewards programs, enrichment for students and organized classroom plan. The headmaster is rated already pursuing programs to increase the competence of teachers. On the other hand teachers' discretion in determining the topic of training is still low. From the qualitative data, it is known that the training undertaken by teachers almost entirely mandatory, not from a teacher training needs analysis. This will potentially lead to a lack of effective efforts to learn in order to improve the knowledge or skills which are priority and in accordance with the needs of teachers so that later become obstacles to increase teachers' personal mastery. This is in line with the statement A.Noe Raymond et. Al (2015) stated that in implementation the learning organization, leaders need to take an active role in identifying the training needs of its members and then make sure that the training is being used in their daily work. Strengthening the potential of teachers can be improved through real-life examples that is directly performed by the principal, or coaching activity to repair performance. The important role of school leadership in empowering teachers through various means has been submitted in one of the conclusions of research conducted Janet Wai-Yin Lo (2004), which states that in developing the learning organization in schools, principals need to take on the role as a role model of learning professionals, principals set the parameters studied including the sharing of knowledge to teachers, explaining the development of macro trend associated with education where headmaster is expected not only to serve as an instructional leader but also a stimulator that facilitates intellectual interaction, earnestly examines the issues related to efforts to improve school performance.

Hypothesis test results also show there is a significant positive relationship between Self Efficacy and Learning Organization with correlation coefficient $(r)=0.214(p<0.01)$. Based on the coefficient of determination $\left(\mathrm{r}^{2}\right)=0.046$, it is concluded that self-efficacy is accounted for $4.6 \%$ of the learning organization. Self-efficacy of teachers will affect their learning activities; in this case the teachers who have strong confidence to successfully carry out the task will be more motivated to engage in actions that will help to perform optimally. This is in line with the statement of John Ivancevich et.al (2011) that high self-efficacy will make someone learn more and willing to transfer learning to improve 
performance and orientate to the level of goal setting and performance higher. Increased confidence can be increased through a new opportunity to carry out various, complex, challenging and prestigious tasks in which to get them done, members need to improve the knowledge and competence through learning activities.

Finally, results of hypothesis testing shows significant positive correlation among knowledge management, empowerment, and self-efficacy simultaneously with a learning organization with the correlation coefficient $=0.834(\mathrm{p}<0.01)$ it can be concluded that the relationship among the three (3) independent variables are very strong to learning organization. Determination coefficient $=0.695$, meaning $69.5 \%$ of learning organization is the result of knowledge management, empowerment and self-efficacy altogether, while $30.5 \%$ is determined by other variables that may have relationship with the increased learning organization of teachers. Commitment of principals in improving the knowledge and skills of teachers through training activities supported by the high ability of teachers in carrying out primary task of educating and managing the class, will create a conducive learning climate. Willingness of principals to share authority and responsibility with the teacher provide an opportunity for teachers to increase knowledge, skills training as well have an impact on ability to collaborate. These activities will ultimately foster a strong learning atmosphere in schools, where teachers are constantly learning, knowledge and skills increase regularly which will ultimately impact the attainment of the objectives of the school and increase the school's competitive advantage.

Furthermore, based on analysis of interviews, focus group discussions, observation and documentation of qualitative research in three schools, several factors are considered related to the teacher learning organization:

- An organizational culture that encourages innovation prioritizes continuous improvement, resultsoriented and process, openness among citizens of organizations expected to support ongoing learning atmosphere among the school community and teachers in particular.

- Effective leadership is the main figure of competent leaders and strive to be an example on how to perform the high standards that will encourage teachers to replicate, make it a source of learning. It takes a leader who values learning outcomes and encourages innovation among teachers so that teachers are encouraged to continue to improve skills.

- Achievement motivation among teachers reinforce the intrinsic driving force for not being quickly satisfied with the results that have been achieved, continue to improve themselves, increase knowledge and skills that support optimality role as educators who are responsible for educational outputs.

- Personality of teachers who are open to change and progress, be flexible to dissent, accept constructive feedback, interact happily to share knowledge and expertise will make easier to accept new ideas and build a positive outlook towards surrounding.

- Supported learning infrastructure is necessary to ensure teachers can access a variety of learning resources to implement sustainable continuous learning activities.

\section{Conclusion}

Based on the analysis, discussion of the results of research and hypotheses that have been tested, it can be concluded there is a significant positive correlation of quantitative research, reinforced with qualitative research, between:

- Knowledge management with learning organization through the regression equation $\mathrm{Y}=41,061+$ $0.628 \mathrm{X} 1$, with a correlation coefficient $=0.814(\mathrm{P}<0.01)$ and the coefficient of determination $=$ 0.662 , thus it can be stated that the higher the knowledge management the higher the learning organization.

- Empowering with learning organization through the regression equation $\mathrm{Y}=86,479+0.274 \mathrm{X} 2$, with a correlation coefficient $=0.302(\mathrm{P}<0.01)$, and the coefficient of determination $=0.091$, thus it can be stated that the higher the empowerment the higher the learning organization.

- Self efficacy with learning organization through the regression equation $Y=96,322+0.197 X 3$, with a correlation coefficient $=0.214(\mathrm{P}<0.01)$, and the coefficient of determination $=0.046$, thus it can be stated that the higher self-efficacy, the higher the learning organization. 


\section{REFERENCES}

[1] Colquitt, Jason A., Jeffery A. Lepine dan Michael J. Wetson. Organizational Behavior: Improving Performance and Commitment in the Workplace. Boston: McGraw Hill. 2011

[2] Feist, Jess, Gregory Feist dan Tomi-Ann Robert. Theories of Personality, 8th Ed. NewYork: McGraw-Hill. 2013

[3] Gibson, James 1., John m. Ivanicevich, James H. Donnelly, Jr dan Robert Konopaske. Organizations, Behavior, Structure, Processes, 14th Ed. New York: McGraw-Hill. 2009

[4] Hawley, Tim. Making Knowledge Management Work for Your Organization. London: Ark Group. 2012

[5] Hersey, Paul, Kenneth H. Blanchard dan Dewey E. Johnson, Management of Organizational Behavior, Leading Human Resources, 9th Ed. New Jersey: Pearson Education, Inc. 2008

[6] Ivanchevich, John M. Robert Konopaske dan Michael T. Matteson. Organizatinal Behavior \& Management, 10th Ed. New York: McGraw-Hill. 2011

[7] Jones, Gareth. Organizational Theory, Design and Change, 7th Ed. Harlow: Pearson Education Limited. 2013

[8] King, William R. "Knowledge Management and Organizational Learning". Annals of Information System 4, Pittsburg: Springer Science+ business Media. 2009

[9] Lo, Janet Wai-Yin, Implementation of the Learning Organization Concept in School Management: a Literatur Review. Nota: International Graduate Scholl of Management, University of South Australia. 2004

[10] Luthans, Fred. Organizational Behavior an Evidence-Based Approach, 12th Ed. New York: Mc Graw-Hill. 2011

[11] Marquardt, Michael J. Building the Learning Organization Mastering 5 Elements for Corporate Learning. Palo Alto, CA: Davies-Black Publishing, Inc. 2002

[12] Noe, Raymond A, John R. Hollenbeck, Barry Gerhart, Patrick M. Wright, Human Resources Management, Gaining a Competitive Advantage, 9th Ed. Berkshire: McGraw-Hill. 2015

[13] Quintas, Paul. Managing Knowledge in a New Century. Managing Knowledge, an Essential Reader. Editor Stephen Little dan Paul Quintas. London: Sage Publications. 2002

[14] Senge, Peter, Nelda Cambron-Mc Cabe, Timothy Lucas, Bryan Smith, Janis Dutton, dan Art Kleiner. Schools That Learn, a Fifth Discipline Field book for Educators, Parents and Everyone Who Cares about Education, Updated \& Revised. New York: Doubleday. 2012 